\title{
Toxic anterior segment syndrome after uncomplicated cataract surgery possibly associated with intracamaral use of cefuroxime
}

This article was published in the following Dove Press journal:

Clinical Ophthalmology

17 March 2015

Number of times this article has been viewed

\author{
Burçin Çakır \\ Erkan Celik \\ Nilgün Özkan Aksoy \\ Özlem Bursalı \\ Turgay Uçak \\ Erdinç Bozkurt \\ Gursoy Alagoz
}

Sakarya University Education and Research Hospital, Sakarya, Turkey

Correspondence: Burçin Çakır Sakarya University Education and Research Hospital, Adnan Menderes Street, Sakarya 54000, Turkey Tel +905326605657

Email b_koklu@yahoo.com
Purpose: To report toxic anterior segment syndrome (TASS) after cataract surgery possibly associated with intracameral use of cefuroxime.

Methods: We conducted a retrospective chart review and analysis on the pre- and postoperative conditions of the subjects who had developed TASS.

Results: The patient group consisted of 17 patients. Tyndallization and fibrin fibers were positive in all eyes. In four eyes, hypopyon formation developed. These reactions diminished on the third day and fully resolved 1 week after the operations with the use of intensive topical steroid and mydriatic therapy. To determine the etiology of TASS, infusion fluid, viscoelastics, and intracameral antibiotic agent were changed respectively. After changing intracameral antibiotic agent from cefuroxime axetile to moxifloxacin no new cases of TASS were diagnosed.

Conclusion: All agents injected into the anterior chamber can cause TASS. Ophthalmologists and operating room staff need to pay careful attention to all drugs and irrigating solutions.

Keywords: phacoemulsification, fibrin reaction, drug toxicity

\section{Introduction}

Toxic anterior segment syndrome (TASS) is postoperative anterior segment inflammation. It usually develops after uncomplicated anterior segment surgery. TASS has also been reported after phakic intraocular lens implantation, penetrating keratoplasty, and intravitreal injection with bevacizumab. ${ }^{1-3}$ Toxic agents associated with TASS include residue solutions used in sterilization, topical disinfectant, and preservatives in medicine used during surgery. ${ }^{4}$

Diffuse corneal edema is usually seen in TASS. Anterior segment reaction with progressive cell, flare, and hypopyon formation and fibrin reaction are also observed. Secondary glaucoma due to iris and trabecular meshwork damage may be seen. Visual outcome changes from 20/20 to no light perception. ${ }^{3,4}$

TASS may be seen as sporadic cases or in outbreaks. Recently reported outbreaks were associated with sterilization methods and endotoxin contamination of balanced salt solution (BSS)..$^{5-8}$ This study describes an outbreak of TASS that appeared after uneventful cataract surgery, possibly due to intracameral use of $1 \mathrm{mg} / 0.1 \mathrm{cc}$ cefuroxime.

\section{Materials and methods}

Seventeen eyes of 17 patients who were diagnosed with TASS were enrolled in this study. All of them underwent uncomplicated phacoemulsification and posterior chamber intraocular lens implantation. Surgeries were performed by two surgeons between 
July 2013 and October 2013. This study followed the tenets of the Declaration of Helsinki, and informed consent was obtained from patients. Institutional Review Board approval was also obtained.

Patients' sex, age, preoperative best-corrected visual acuity (BCVA), intraocular pressure (IOP), and history of systemic and ocular diseases were evaluated as preoperative conditions. Intraoperative conditions were surgeon-specific effects, order of surgery, phaco machine variation, viscoelastics, type of intraocular lens, irrigating solutions, intracameral agents, and the method used to sterilize the surgical instruments. Postoperatively, BCVA and IOP measurements and biomicroscopic examination were performed on the first day, third day, and after 1 week.

Prior to the operation, tropicamide $1 \%$ and phenylephrine hydrochloride $2.5 \%$ were applied to patients' eyes for pupil dilation. Powder-free gloves were used routinely in all surgeries. Operations were performed under topical anesthesia achieved by proparacaine $\mathrm{HCl} 0.5 \%$. Eyelids, eyelashes, and conjunctiva were disinfected with povidone-iodine $5 \%$. BSS Plus $^{\circledR}$ and lactated ringer solutions were used as infusion fluid. Two different dispersive viscoelastics (Viscoat ${ }^{\circledR}$ and BiVISC ${ }^{\mathrm{TM}}$ ) and two different cohesive viscoelastics (Healon ${ }^{\circledR}$ and Bio-Hyalur 3\%) were used during cataract surgery. Viscoelastics were cleaned out with marked attention, even behind the intraocular lenses. Phacoemulsification was performed with AMO Whitestar Signature Phaco System. The stop-chop technique was used in all surgeries. A one-piece hydrophobic acrylic intraocular lens (Sensar ${ }^{\circledR}$ model: AAB00) was used in all surgeries. No intraoperative complications occurred. The procedure ended with intracameral cefuroxime axetil $1 \mathrm{mg} / 0.1 \mathrm{cc}$ for endophthalmitis prophylaxis, as recommended in the European Society of Cataract and Refractive Surgeons Endophthalmitis Study Group (ESCRS) study of prophylaxis of postoperative endophthalmitis. ${ }^{9}$ The medications and instruments used intraoperatively were no different from those used routinely. Surgical instruments were the same in all operations. There had been no changes in the operation room, sterilization devices, or the operative team, and the two surgeons had no other cases of TASS beforehand or later on.
Postoperatively, topical ophthalmic ointments were not used. Topical steroid drops (prednisolone acetate 1\%) and topical antibiotics (ofloxacin $0.3 \%$ ) were used every hour with gradual tapering.

\section{Results}

The patient group consisted of six male and eleven female patients. The average age of the patients was $72.3 \pm 8.1$ years. All patients had hypertension, and two of them had type 2 diabetes mellitus. The patients had no history of other ocular pathology. Types of cataracts were diagnosed as mature cataract for three patients, nuclear sclerosis for ten patients, and posterior subcapsular cataract for four patients. Preoperative BCVA ranged between light perception-projection and 0.3 . Mean preoperative IOP was $14.5 \pm 2 \mathrm{mmHg}$. Postoperative BCVA increased, and IOP remained in the normal range in the first week (Table 1).

Tyndallization was positive in all eyes on the first postoperative day in various degrees. Fibrin fibers were observed in all eyes. Fibrin fibers were present on the iris and the anterior surface of the intraocular lens. In six eyes, these fibers extended toward the corneal tunnel and paracentesis incisions (Figure 1). In four eyes, $2 \mathrm{~mm}$ hypopyon formation developed 1 day after the surgery (Figure 2). These reactions diminished on the third day and fully resolved 1 week after the surgery with the use of intensive topical steroid and mydriatic therapy. Mild corneal edema was found in all eyes, which resolved gradually with topical steroid therapy. Conjunctival hyperemia was minimal, and patients did not have pain compared with severe anterior chamber inflammation. Eyelid edema was not observed in any patient. Visualization of the posterior segment was poor, but red light reflex was observed clearly in all patients. Despite these anterior segment reactions, BCVA improved in all eyes, and IOP did not increase to pathological levels (Table 2).

The surgeries were performed in the same operating room by two experienced surgeons, with the attendance of the same nurse. Surgical time for each surgery did not exceed 30 minutes.

Table I IOP and BCVA changes of patients diagnosed with toxic anterior segment syndrome

\begin{tabular}{llll}
\hline & Preoperative & Postoperative third day & Postoperative first week \\
\hline Mean BCVA \pm SD & $0.12 \pm 0.1$ & $0.34 \pm 0.1$ & $0.52 \pm 0.1$ \\
Mean IOP \pm SD & $14.5 \pm 2 \mathrm{mmHg}$ & $13.7 \pm 2 \mathrm{mmHg}$ & $14.2 \pm 1.9 \mathrm{mmHg}$ \\
\hline
\end{tabular}

Abbreviations: IOP, intraocular pressure; BCVA, best-corrected visual acuity; SD, standard deviation. 


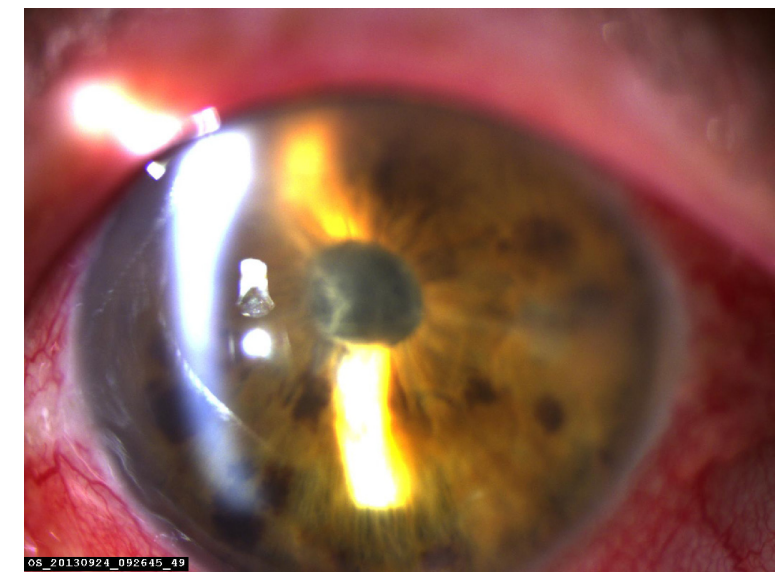

Figure I Fibrin reaction extended as far as paracentesis.

We contacted the manufacturing companies of the intraocular lenses, viscoelastics, phaco machine, and tubing systems, and they informed us that there were no cases like ours reported for those materials with similar lot numbers. We did not find any sign related to surgeons, nurses, order of surgery, or sterilization method.

TASS was diagnosed in six eyes of 62 patients who underwent phaco surgery in 2 months. To determine the etiology, infusion fluid was changed from 5\% BSS Plus ${ }^{\circledR}$ to lactated ringer solution. Despite this change, TASS occurred in six eyes of 56 patients in 2 months. Then, dispersive and cohesive viscoelastics were changed. After this precaution, TASS was diagnosed in five eyes of 40 eyes that underwent surgery in 1 month. Lastly, the intracameral antibiotic was changed to $250 \mu \mathrm{g} / 0.1 \mathrm{cc}$ moxifloxacin. After this change, TASS did not occur. Since October 2013 until January 2014, approximately 360 phaco surgeries have been performed and TASS did not occur.

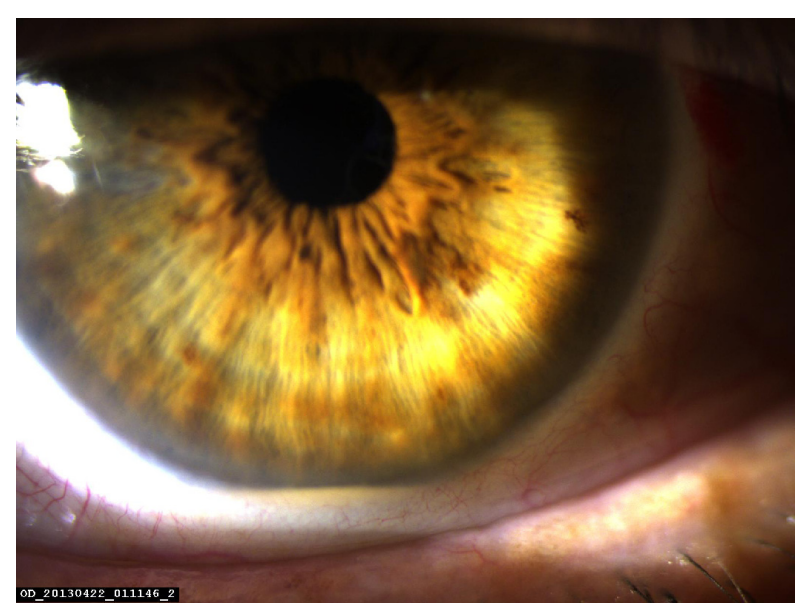

Figure 2 Hypopyon formation.
Table 2 Anterior segment findings of patients on the first day of surgery

\begin{tabular}{ll}
\hline Anterior segment findings & Number of patients \\
\hline Corneal edema & 10 \\
Fibrin reaction & 17 \\
Fibrin reaction elongate toward incisions & 6 \\
Hypopyon formation & 4 \\
\hline
\end{tabular}

\section{Discussion}

It is important to differentiate TASS from bacterial endophthalmitis. TASS usually occurs within 24 hours after surgery. Clinical findings are in the anterior segment and respond to steroid treatment. Bacterial endophthalmitis usually occurs 4-7 days after surgery and may also affect vitreous. Lid edema, conjunctival injection, and pain can accompany other findings. ${ }^{10}$ In the cases reported in this study, corneal edema and anterior chamber reaction developed within 24 hours after surgery. No conjunctival injection or pain was seen and we diagnosed these cases as TASS.

The etiology of TASS seems to be multifactorial. Recent outbreaks of TASS are mostly related to sterilization issues, improper reconstitutions of intraocular preparations, residues from denatured ophthalmic viscoelastic devices, and endotoxin contamination of BSS. ${ }^{11}$ In our clinic, nurses and other personnel are well educated about the cleaning and sterilization processes. After every case of TASS, we strictly checked modes of sterilization and ventilation systems, and these systems did not change during this period.

A multistate outbreak of TASS was reported in recent years. ${ }^{6}$ This report identified 112 cases from seven centers. One hundred patients $(89 \%)$ had been exposed to a single brand of BSS. The change of BSS resolved the anterior segment reaction. We also suspected infusion fluid and changed BSS Plus $^{\circledR}$ to lactated ringer. After the infusion fluid was changed, TASS continued to occur.

An experimental randomized animal study investigated the ocular reactivity of rabbits to bacterial endotoxin contained in an ophthalmic viscosurgical device. ${ }^{12}$ The anterior segment inflammation, especially fibrin accumulation, was seen due to very little amounts of endotoxin that are contained in ophthalmic viscosurgical devices. In our cases, fibrin reaction is the most important and common sign of TASS. We changed viscoelastics and carefully rinsed residue viscoelastics from the anterior chamber at the end of the surgery. After these precautions, we saw new cases with TASS.

In our clinic, intracameral cefuroxime had been used routinely at the end of the surgery. We suspected this 
intracameral agent and changed it to $250 \mu \mathrm{g} / 0.1 \mathrm{cc}$ moxifloxacin. After this change, TASS did not occur.

The use of cefuroxime $1 \mathrm{mg} / 0.1 \mathrm{cc}$ at the end of cataract surgery is very common since the beneficial results were first reported by the ESCRS in $2006 .{ }^{9}$ The study by the ESCRS was recently updated. ${ }^{13}$ Seventy-four percent of surgeons always used intracameral cefuroxime. The most frequently cited reasons for not using cefuroxime were the lack of an approved commercial preparation and related anxieties regarding the risk of dilution errors and contamination. More than $90 \%$ of respondents said they would use cefuroxime if an approved single-unit dose product was commercially available. Lockington et $\mathrm{al}^{14}$ revealed that the mathematical accuracy of a dilution protocol does not ensure dosage accuracy in the clinical scenario. They indicated that smallvolume syringes should not be used for preparation of this drug. Yoeruek et $\mathrm{al}^{15}$ showed that cefuroxime concentrations higher than $2.75 \mathrm{mg} / \mathrm{mL}$ led to significant reduction in cell viability. These data suggest a dose-dependent toxicity of cefuroxime on human corneal endothelial cells in vitro with a narrow range of safety. Free radicals, especially hydrogen peroxide, are known to be present in ophthalmic preparations. Lockington et $\mathrm{al}^{16}$ revealed that phenylephrine, cefuroxime, $2 \%$ undiluted lidocaine, and bevacizumab had the highest presence of free radicals. These radicals may cause endothelial damage and anterior segment reaction. On the other hand, Lam et $\mathrm{al}^{17}$ reported no significant differences in the changes of endothelial cell density and central macular thickness between eyes receiving intracameral cephalosporin including cefuroxime and the control group. Montan et al ${ }^{18}$ also reported no corneal damage and irreversible effect of intracameral use of cefuroxime.

To determine the responsible agent, we replaced cefuroxime with intracameral moxifloxacin, after which, TASS did not occur in any cataract surgery.

Intracameral moxifloxacin has been reported as nontoxic to anterior segment and corneal endothelial cells in both experimental animal studies and clinical studies. ${ }^{19-25}$

In summary, eye surgeons and operating room personnel should be careful about all drugs that are used intracamerally during cataract surgery. Types and concentrations of drugs must be controlled strictly. In addition, it is recommended to use approved commercial and single-unit products to avoid the risk of dilution errors and contamination.

\section{Disclosure}

The authors report no conflicts of interest in this work.

\section{References}

1. Sorkin N, Varssano D. Toxic anterior segment syndrome following a triple Descemet's stripping automated endothelial keratoplasty procedure. Case Rep Ophthalmol. 2012;3(3):406-409.

2. Van Philips LA. Toxic anterior segment syndrome after foldable artiflex iris-fixated phakic intraocular lens implantation. $J$ Ophthalmol. 2011;2011:982410.

3. Sato T, Emi K, Ikeda T, et al. Severe intraocular inflammation after intravitreal injection of bevacizumab. Ophthalmology. 2010; 117(3):512-516.

4. Cutler Peck CM, Brubaker J, Clouser S, Danford C, Edelhauser HE, Mamalis N. Toxic anterior segment syndrome: common causes. J Cataract Refract Surg. 2010;36(7):1073-1080.

5. Sarobe Carricas M, Segrelles Bellmunt G, Jiménez Lasanta L, Iruin Sanz A. Toxic anterior segment syndrome (TASS): studying an outbreak. Farm Hosp. 2008;32(6):339-343.

6. Kutty PK, Forster TS, Wood-Koob C, et al. Multistate outbreak of toxic anterior segment syndrome, 2005. J Cataract Refract Surg. 2008;34(4):585-590.

7. Unal M, Yücel I, Akar Y, Oner A, Altin M. Outbreak of toxic anterior segment syndrome associated with glutaraldehyde after cataract surgery. $J$ Cataract Refract Surg. 2006;32(10):1696-1701.

8. Hellinger WC, Hasan SA, Bacalis LP, et al. Outbreak of toxic anterior segment syndrome following cataract surgery associated with impurities in autoclave steam moisture. Infect Control Hosp Epidemiol. 2006;27(3):294-298.

9. Barry P, Seal DV, Gettinby G, Lees F, Peterson M, Revie CW; ESCRS Endophthalmitis Study Group. ESCRS study of prophylaxis of postoperative endophthalmitis after cataract surgery: preliminary report of principal results from a European multicenter study. J Cataract Refract Surg. 2006;32(3):407-410.

10. Jiang $\mathrm{J}, \mathrm{Wu} \mathrm{M}$, Shen $\mathrm{T}$. The toxic effect of different concentrations of povidone iodine on the rabbit's cornea. Cutan Ocul Toxicol. 2009;28(3):119-124.

11. Bodnar Z, Clouser S, Mamalis N. Toxic anterior segment syndrome: update on the most common causes. J Cataract Refract Surg. 2012;38(11):1902-1910.

12. Buchen SY, Calogero D, Hilmantel G, Eydelman MB. Rabbit ocular reactivity to bacterial endotoxin contained in aqueous solution and ophthalmic viscosurgical devices. Ophthalmology. 2012;119(7):e4-e10.

13. Barry P. Adoption of intracameral antibiotic prophylaxis of endophthalmitis following cataract surgery: update on the ESCRS Endophthalmitis Study. J Cataract Refract Surg. 2014;40(1):138-142.

14. Lockington D, Flowers H, Young D, Yorston D. Assessing the accuracy of intracameral antibiotic preparation for use in cataract surgery. $J$ Cataract Refract Surg. 2010;36(2):286-289.

15. Yoeruek E, Spitzer MS, Saygili O, et al. Comparison of in vitro safety profiles of vancomycin and cefuroxime on human corneal endothelial cells for intracameral use. J Cataract Refract Surg. 2008;34(12):2139-2145.

16. Lockington D, MacdonaldEC, Young D, Stewart P, Caslake M, Ramaesh K. Presence of free radicals in intracameral agents commonly used during cataract surgery. Br J Ophthalmol. 2010;94(12):1674-1677.

17. Lam PT, Young AL, Cheng LL, Tam PM, Lee VY. Randomized controlled trial on the safety of intracameral cephalosporins in cataract surgery. Clin Ophthalmol. 2010;8(4):1499-1504.

18. Montan PG, Wejde G, Setterquist H, Rylander M, Zetterström C. Prophylactic intracameral cefuroxime. Evaluation of safety and kinetics in cataract surgery. J Cataract Refract Surg. 2002;28(6):982-987.

19. Matsuura K, Miyoshi T, Suto C, Akura J, Inoue Y. Efficacy and safety of prophylactic intracameral moxifloxacin injection in Japan. J Cataract Refract Surg. 2013;39(11):1702-1706.

20. Asena L, Akova YA, Goktaş MT, et al. Ocular pharmacokinetics, safety and efficacy of intracameral moxifloxacin $0.5 \%$ solution in a rabbit model. Curr Eye Res. 2013;38(4):472-479. 
21. Ekinci Koktekir B, Aslan BS. Safety of prophylactic intracameral moxifloxacin use in cataract surgery. J Ocul Pharmacol Ther 2012;28(3):278-282.

22. Kobayakawa S, Hiratsuka Y, Watabe Y, Murakami A, Tochikubo T. Comparison of the influence of intracameral gentamicin, gatifloxacin, and moxifloxacin on the corneal endothelium in a rabbit model. Jpn J Ophthalmol. 2010;54(5):481-485.

23. Lane SS, Osher RH, Masket S, Belani S. Evaluation of the safety of prophylactic intracameral moxifloxacin in cataract surgery. J Cataract Refract Surg. 2008;34(9):1451-1459.
24. Kim SY, Park YH, Lee YC. Comparison of the effect of intracameral moxifloxacin, levofloxacin and cefazolin on rabbit corneal endothelial cells. Clin Experiment Ophthalmol. 2008;36(4):367-370.

25. Espiritu CR, Caparas VL, Bolinao JG. Safety of prophylactic intracameral moxifloxacin $0.5 \%$ ophthalmic solution in cataract surgery patients. J Cataract Refract Surg. 2007;33(1):63-68.

\section{Publish your work in this journal}

Clinical Ophthalmology is an international, peer-reviewed journal covering all subspecialties within ophthalmology. Key topics include: Optometry; Visual science; Pharmacology and drug therapy in eye diseases; Basic Sciences; Primary and Secondary eye care; Patien Safety and Quality of Care Improvements. This journal is indexed on

Submit your manuscript here: http://www.dovepress.com/clinical-ophthalmology-journal

\section{Dovepress}

PubMed Central and CAS, and is the official journal of The Society of Clinical Ophthalmology (SCO). The manuscript management system is completely online and includes a very quick and fair peer-review system, which is all easy to use. Visit http://www.dovepress.com/ testimonials.php to read real quotes from published authors. 